\title{
OBTAINING AND RESEARCH OF ELECTRODEPOSITED CHROMIUM NANODIAMOND COATINGS
}

\author{
Julia AVERINA, Galina KALYAKINA, Elena SUBCHEVA, Ekaterina ABAEVA, Andrey KURBATOV \\ Russian University of Chemical Technology D.I. Mendeleev, Moscow, Russia, \\ averinajm@mail.ru
}

https://doi.org/10.37904/metal.2021.4175

\begin{abstract}
The paper presents the results of electrodeposition for obtaining chromium coatings with the addition of nanodiamonds with a thickness of 10 and $50 \mu \mathrm{m}$. The topography of the coatings was investigated by scanning electron microscopy (SEM), and the qualitative composition by energy dispersive microanalysis (EDX). Potential use as coatings for detail parts has been identified. The hardness and wear resistance of chrome coatings have been investigated. It is shown that the addition of 1 mass. \% of nanodiamonds in the electrolyte significantly improves the properties of the coating even at a thickness of $10 \mu \mathrm{m}$.
\end{abstract}

Keywords: Chromium, protective coating, electrodeposition, nanodiamond coatings

\section{INTRODUCTION}

Chromium is widely used as a protective coating, as well as for shiny luster such as auto parts or home accessories. Chromium coatings can improve corrosion resistance, hardness, and resistance to aggressive environments in addition to improving wear resistance [1]. Electrodeposition is the main industrial chromium plating method today. This method has a such of problems, in particular: coarse deposition of chromium, insufficient thickness and hardness [2]. Each stage requires strict adherence to the technological regulations, which, depending on the substrate on which the deposition takes place and the conditions of further operation, has significant differences and is selected individually. Modern research is carried out in the field of new compositions of electrolytes, as well as the addition of various substances to improve the resulting coatings [3-6]. The purpose of this study is to develop a composition, as well as obtain chromium nanodiamond coatings with improved characteristics.

\section{EXPERIMENTAL AND DISCUSS OF RESULTS}

Chromium-diamond coatings were obtained by electrodeposition, using a mixture of nanodispersed particles of diamonds of static synthesis with a range of particle sizes from 2 to $300 \mathrm{~nm}$, as seen in (Figure 1). Control of the size of nanoparticles was carried out by transmission electron microscopy. Coatings of different thickness were obtained on a standard electrolyte $\left(\mathrm{CrO}_{3}-250 \mathrm{~g} / \mathrm{l}, \mathrm{H}_{2} \mathrm{SO}_{4}-2,5\right.$ $\mathrm{g} / \mathrm{ll})$ in wear-resistant chrome plating mode $\left(55^{\circ} \mathrm{C}\right)$ with a cathode current density of $50-60 \mathrm{~A} / \mathrm{dm}^{2}$. It should be noted that higher current densities, as a rule, give better results in terms of the quality of the coating, however, they are rarely used in industry due to their high cost and inconvenience in operation (strong gas evolution, electrolyte splashing, difficulty in maintaining temperature).

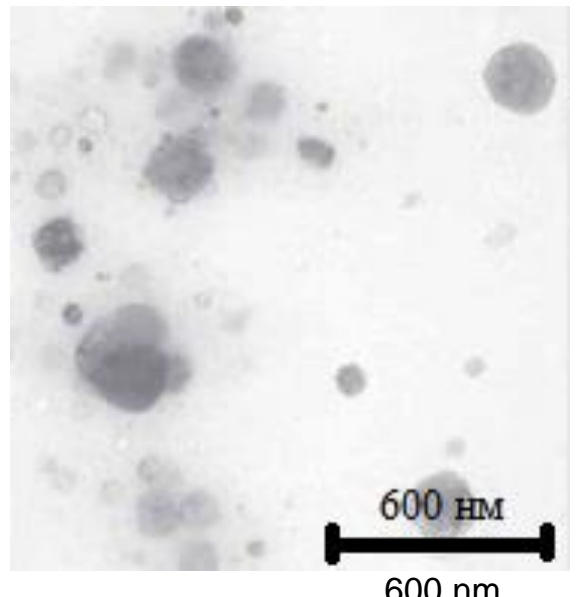

Figure 1 TEM micrograph of diamond nanoparticles 
As a result of the deposition, chromium-diamond coatings with a predetermined thickness of $10 \mu \mathrm{m}$ and $50 \mu \mathrm{m}$ were obtained. The exact thickness of the obtained coatings was determined using an OLYMPUS LEXT OLS4100 confocal laser scanning microscope. For research, three microsections were prepared with a crosssection of the coating, which were then polished. The results are shown in (Figure 2).



a

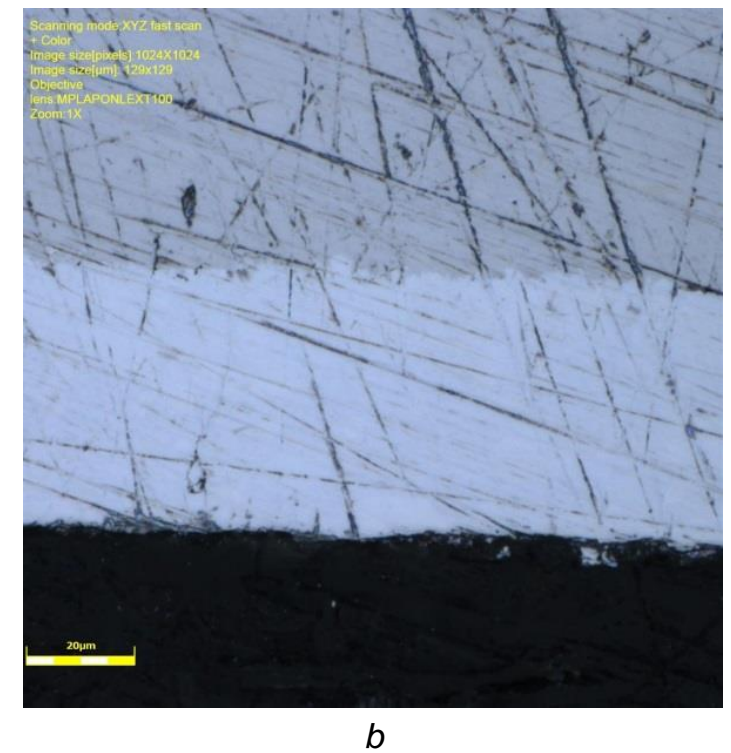

$b$

Figure 2 Images obtained by measuring the coating thickness on an OLYMPUS LEXT OLS4100 microscope: a sample with an assumed thickness of a) $10 \mu \mathrm{m}$, b) $50 \mu \mathrm{m}$

The exact values of the thickness for the samples were: $11.8 \pm 0.2 \mu \mathrm{m}$ and $46.3 \pm 0.2 \mu \mathrm{m}$, which corresponds to the specified range. It should be noted that the determination of the roughness on the microscope showed the arithmetic mean of the absolute values of the profile deviations at a distance of the base length of 0.336 and 0.395 microns.

The microstructure of the surface and the qualitative composition were determined by scanning electron microscopy with an attachment for energy dispersive microanalysis on a scanning electron microscope JEOL JSM 6510 LV + SSD X-MAX of the Center for Collective Use. DI. Mendeleev. As can be seen from (Figure 3), the coating is a continuous layer without pores and significant flaws. A larger increase shows the presence of agglomerates of particles on the surface, which can probably be explained by the uneven distribution of nanodiamonds in the coating (taking into account the size and shape of the particle surface). In this case, energy dispersive microanalysis shows the presence of carbon in the coating of the order of $5 \mathrm{wt} \%$.

The most characteristic indicator in this case is the microhardness of the coatings, which is characteristic for industrial applications. The data on the obtained microhardness of the coating without additives of nanodiamonds and with an additive for coating of $10 \mu \mathrm{m}$ are 858 and $932 \mathrm{~kg} / \mathrm{mm}^{2}$, respectively. Taking into account that nanodiamonds will increase the cost of coatings by no more than $15 \%$, these values are significant.

Separately, it should be noted that the use of this type of electrolyte at industrial scale can cause significant damage to the environment. Unfortunately, from an economic point of view, replacing chromium can significantly increase the cost, therefore, it is necessary to include wastewater treatment in the industrial design stage of chromium plating. In this case, both traditional and new methods of recovery and deposition can be used [7-10]. 


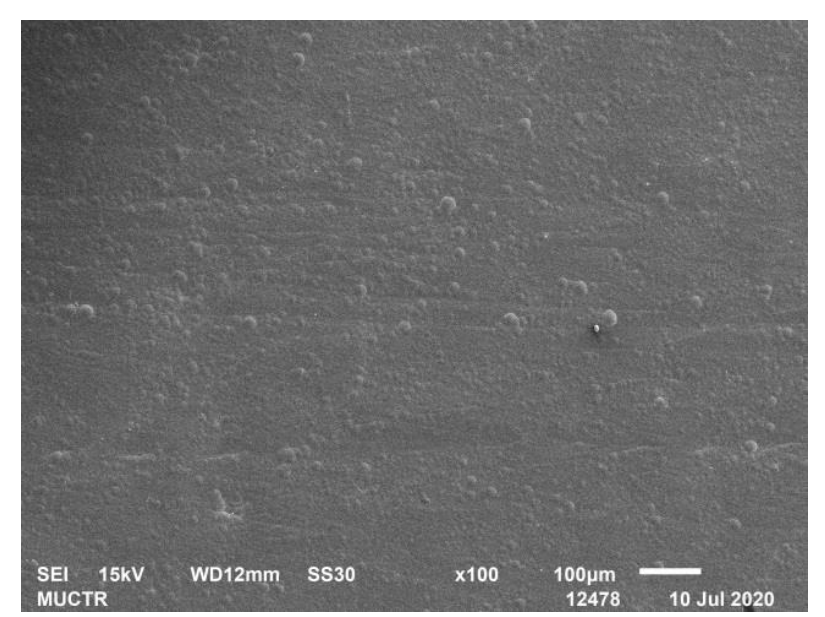

a

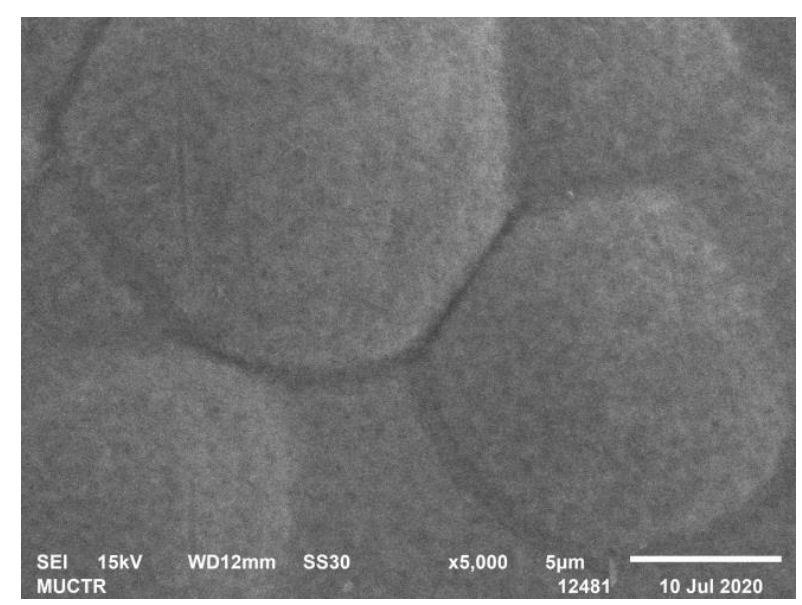

C

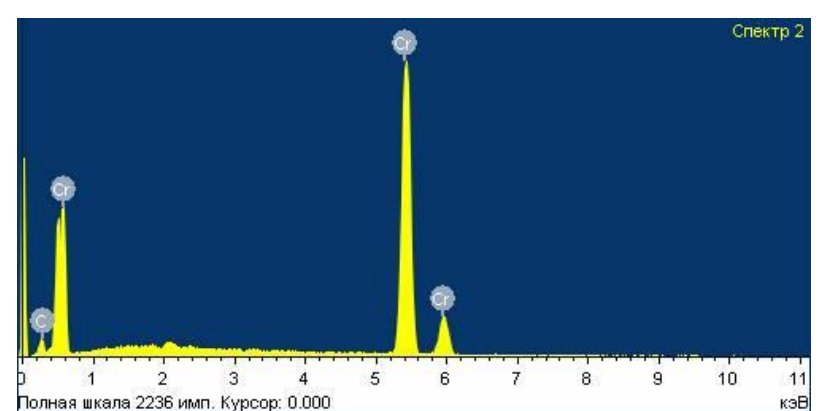

e

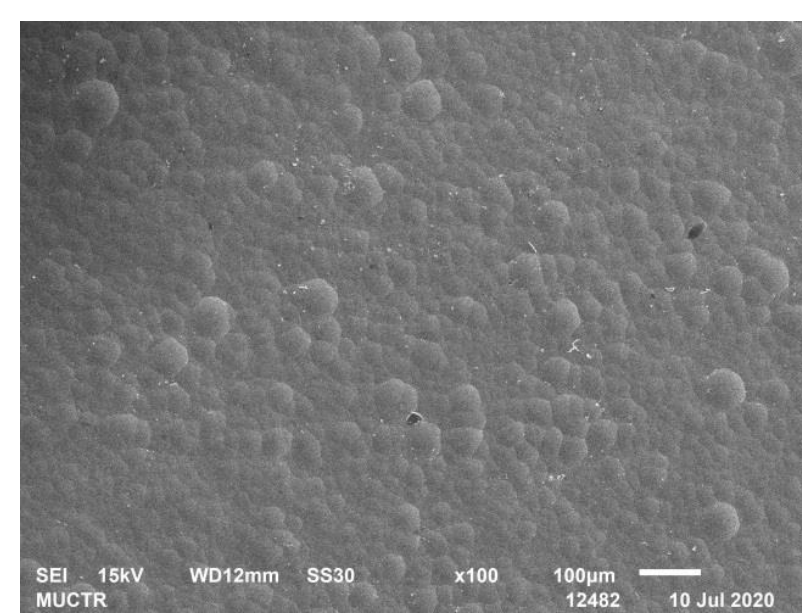

$b$
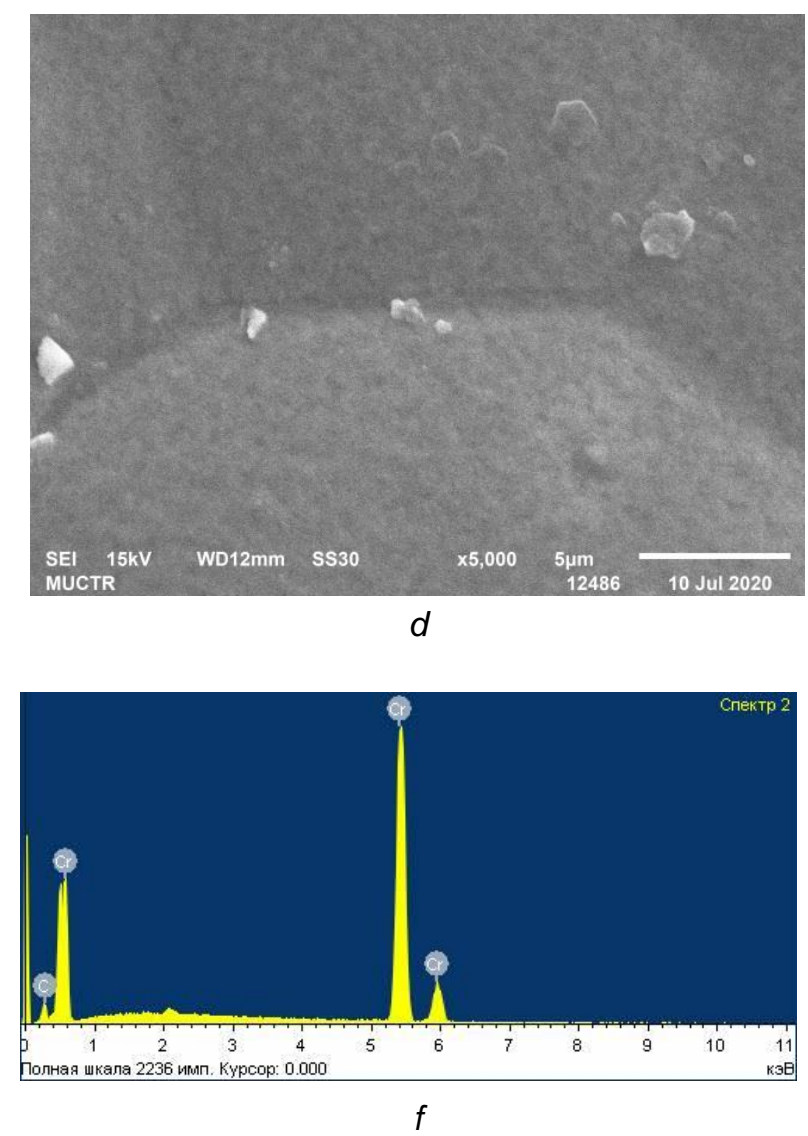

Figure 3 SEM micrographs (a-d) and spectra of energy dispersive microanalysis (e, f) of samples $10 \mu \mathrm{m}$ thick (a, c, e) and $50 \mu \mathrm{m}(\mathrm{b}, \mathrm{d}, \mathrm{f})$.

\section{CONCLUSION}

Thus, due to its more pore-free structure, the chromium-diamond coating also has a higher corrosion resistance. Thus, having better properties, the proposed coatings at a cost of $10-15 \%$ higher than hard chromium plating, can double or more to increase the operating time of parts and assemblies operating under conditions of abrasive and corrosive wear. 


\section{ACKNOWLEDGMENTS}

The work was carried out within the framework of an internal initiative grant of the $D$. Mendeleev

University of Chemical Technology of Russia to support young scientists-teachers in strategic directions of development of the D. Mendeleev University of Chemical Technology of Russia No. X2020-011.

\section{REFERENCES}

[1] FAVAROB, G., and PANTICA, M. "Influence of the surface roughness on adhesion of chrome coatings on alloy tool steel x165crmov12." Journal of the Balkan Tribological Association. 2012, vol 18, no. 2, pp. 228-237.

[2] BAYRAMOGLU, M., ONAT, B. and GEREN, N. "Statistical optimization of process parameters to obtain maximum thickness and brightness in chromium plating." Journal of Materials Processing Technology. 2008, vol. 203, no. 13, pp. 227-286.

[3] PODGORNIK, B., et al. "Crack density and tribological performance of hard-chrome coatings." Tribology International. 2018, vol. 121, pp. 333-340.

[4] YUSRON, R. M., BISONO, R. M. and PRAMUDIA, M. "Effect Electrolyte Temperature and Electrode Distance to Electroplating Hard-Chrome on Medium-Carbon Steel." Journal of Physics: Conference Series. IOP Publishing, 2020, vol. 1569. no. 4.

[5] ALOGAB, K. A., et al. "Fabrication of Chromium Coatings with Carbon Nanotube Additives." Protection of Metals and Physical Chemistry of Surfaces. 2018, vol. 54 no. 3, pp. 360-364.

[6] XU, LINGYUN, et al. "Electroplating of Thick Hard Chromium Coating from a Trivalent Chromium Bath Containing a Ternary Complexing Agent: A Methodological and Mechanistic Study." ACS Sustainable Chemistry \& Engineering. 2020, vol. 8, no. 41, pp. 15540-15549.

[7] KUZIN, E. N., et al. "The purification of the galvanic industry wastewater of chromium (VI) compounds using titanium (III) chloride." Russian Journal of General Chemistry. 2018, vol. 88, no. 13, pp. 2954-2957.

[8] KUZIN, E. N., et al. "Wastewater treatment for galvanic production using complex coagulants-reducing agents." Non-ferrous metals 2019, vol. 10, no. 91.

[9] KUZIN, E. N., et al. "Synthesis of Titanium Trichloride." Inorganic Materials. 2020, vol. 56, pp. 507-511.

[10] KUZIN Evgeny Nikolaevich, KRUCHININA Natalya Evgenievna. "Complex coagulants for electroplating wastewater treatment." Electroplating and Surface Treatment. 2019, vol. 27, no. 4, pp. 43-49. 